Article

\title{
Investigation on the Sensitivity of Ultrasonic Test Applied to Reinforced Concrete Beams Using Neural Network
}

\author{
Jason Maximino C. Ongpeng ${ }^{1, *(\mathbb{D})}$, Andres Winston C. Oreta ${ }^{1}$ and Sohichi Hirose ${ }^{2}$ (i) \\ 1 Department of Civil Engineering, De La Salle University, 2401 Taft Avenue, Manila 1004, Philippines; \\ andres.oreta@dlsu.edu.ph \\ 2 Department of Civil Engineering, Tokyo Institute of Technology, Meguro Ookayama 2-12-1, \\ Tokyo 152-8552, Japan; hirose.s.aa@m.titech.ac.jp \\ * Correspondence: jason.ongpeng@dlsu.edu.ph
}

Received: 1 February 2018; Accepted: 5 March 2018; Published: 9 March 2018

\begin{abstract}
An experiment on reinforced concrete beams using four-point bending test during an ultrasonic test was conducted. Three beam specimens were considered for each water/cement ratio (WC) of $40 \%$ and $60 \%$, with three reinforcement schedules named design A (comprising two top bars and two bottom bars), design $B$ (with two bottom bars), and design $C$ (with one bottom bar). The concrete beam had a size of $100 \mathrm{~mm} \times 100 \mathrm{~mm} \times 400 \mathrm{~mm}$ in length with a plain reinforcement bar of $9 \mathrm{~mm}$ in diameter. An ultrasonic test with pitch-catch configuration was conducted at each loading with the transducers oriented in direct transmission across the beams' length with recordings of 68 datasets per beam specimen. Recordings of ultrasonic test results and strains at the top and bottom surfaces subjected to multiple step loads in the experiment were done. After the collection of the data, feed-forward backpropagation artificial neural network (ANN) was used to investigate the sensitivity of the ultrasonic parameters to the mechanical load applied. Five input parameters were examined, as follows: neutral axis (NA), fundamental harmonic amplitude (A1), second harmonic amplitude (A2), third harmonic amplitude (A3), and peak-to-peak amplitude (PPA), while the output parameter was the percentage of ultimate load. Optimum models were chosen after training, validating, and testing $60 \mathrm{ANN}$ models. The optimum model was chosen on the basis of the highest Pearson's Correlation Coefficient $(R)$ and soundness, confirming that it exhibited good behavior in agreement with theories. A classification of sensitivity was performed using simulations based on the developed optimum models. It was found that A2 and NA were sensitive to all WC and reinforcements used in the ANN simulation. In addition, the range of sensitivity of A2 and NA was inversely and directly proportional to the reinforcing bars, respectively. This study can be used as a guide in the selection of ultrasonic parameters to assess damage in concrete with low or high WC and varying reinforcement content.
\end{abstract}

Keywords: non-destructive test; concrete; ultrasonic; bending; neural network

\section{Introduction}

In modern infrastructures, structural health monitoring is essential to assess and diagnose the current situation before retrofit and repair commences. The common building material used is reinforced concrete. Reinforced concrete can be assessed on the basis of factors such as time, cost, and idle period. For practical reasons, researchers focus on developing non-destructive tests for the fast and economical assessment of a structure with better sensitivity to internal damage against load.

Reinforced concrete comprises two main materials that, when combined together, perform well against aging and mechanical damage. The first material is concrete, which is very good in compression 
and consists of water, cement, sand, aggregates, and sometimes admixtures. This material is very complex in itself because different mixtures, curing methods, sizes of aggregates, and methods of placements can cause inconsistent voids, segregation of aggregates, variable interfacial transition zones, and varying compressive strengths. The sensitivity to internal damage using a nondestructive test such as acoustic emission was explored in plain concrete materials [1,2]. Sensitivity to damage of a nondestructive test parameter is present when the parameter's values are widely spread during low to high application of load. On the other hand, an insensitive parameter is characterized by an abrupt change, showing sudden failure of the materials. This situation is not ideal for structural health monitoring since there is no sign before failure occurs. The second material in reinforced concrete is the addition of reinforced steel bars to increase the tensile capacity of the structure, especially when bending occurs. There are still limited studies on the sensitivity of nondestructive tests in reinforced concrete structures [3,4].

In this paper, an ultrasonic test was done on beams with varying reinforcements. The analysis of the ultrasonic test results against load is very complicated since there is a nonlinear relationship of parameters that influence the damage resulting from the applied load. In addition, the neutral axis was recorded using strain gauges in the midpoint of both faces at the top and bottom. Furthermore, feed-forward backpropagation artificial neural network (ANN) was used as a tool to establish a model using available datasets for the prediction of the damage represented by the load applied. These ANN models were used to simulate and investigate the sensitivity of each parameter, classified as short- and long-range sensitivity. A similar study was done in plain concrete cubes, and it was found that the second harmonic amplitude and strain greatly influences the stress level of plain concrete cubes [5]. Limited research explored the ultrasonic test, and especially the nonlinear ultrasonic test, applied to reinforced concrete beams. This paper illustrates the ability of ANN to obtain a good simulation in order to define a guide to select ultrasonic parameters based on sensitivity, useful when assessing damage for concrete with low or high water/cement ratio (WC) and varying reinforcement content.

\subsection{Ultrasonic Test}

In linear ultrasonic test, the received waveform is not significantly different from the transmitted waveform. One application of this is ultrasonic pulse velocity test wherein distance of transmitter to receiver and time of the wave traveling that distance are the parameters as shown in Equation (1).

Ultrasonic pulse velocity $(\mathrm{UPV})=$ distance of transmitter to receiver/time to travel

The time to travel of the longitudinal wave from transmitter to receiver is shown in Figure 1 and is used to compute the ultrasonic pulse velocity. It is observed that sizes of cracks greater than $100 \mathrm{~mm}$ are the only ones detected by longitudinal ultrasonic pulses [6]. Additional study claims that cracks are not detected with accuracy especially if it is filled up with fluids. Another parameter used in linear ultrasonic test in time-domain wave form is peak to peak amplitude (PPA) of the received waveform. It is used as a measurement in damage detection. It is the vertical distance from the highest point to the lowest point of the time-domain waveform. It shows that PPA has also been one of the significant parameters in estimating the residual strength of concrete where reduction of PPA is experienced when the load is increased $[7,8]$.

On the other hand, nonlinear ultrasonic test method focuses on spectral frequency analysis. This is a phenomenon resulting from interaction between ultrasonic wave and concrete [9]. During the interaction of the load and material, a part of the fundamental frequency is converted to higher harmonics shown in Figure 2 where A1 is the fundamental harmonic amplitude, A2 is the second harmonic amplitude and $\mathrm{A} 3$ is the third harmonic amplitude. Harmonic generation will not occur without attenuation. Attenuation is the reduction in intensity during the wave's travel through a material. Moreover, internal friction between surfaces contributes to the attenuation. Occurrence of higher harmonic generation is due to contact of crack interfaces called Contact Acoustic Nonlinearity [10-13]. The concrete, when loaded, experiences opening and closing of cracks and/or 
frictional forces acting on the interfaces between cement paste and the aggregates. The higher harmonics generated depend on the cracks forming inside when compressive load is applied [14] and interact with the defects, causing the opening/closing of the cracks formed when loading and unloading occurs $[15,16]$.

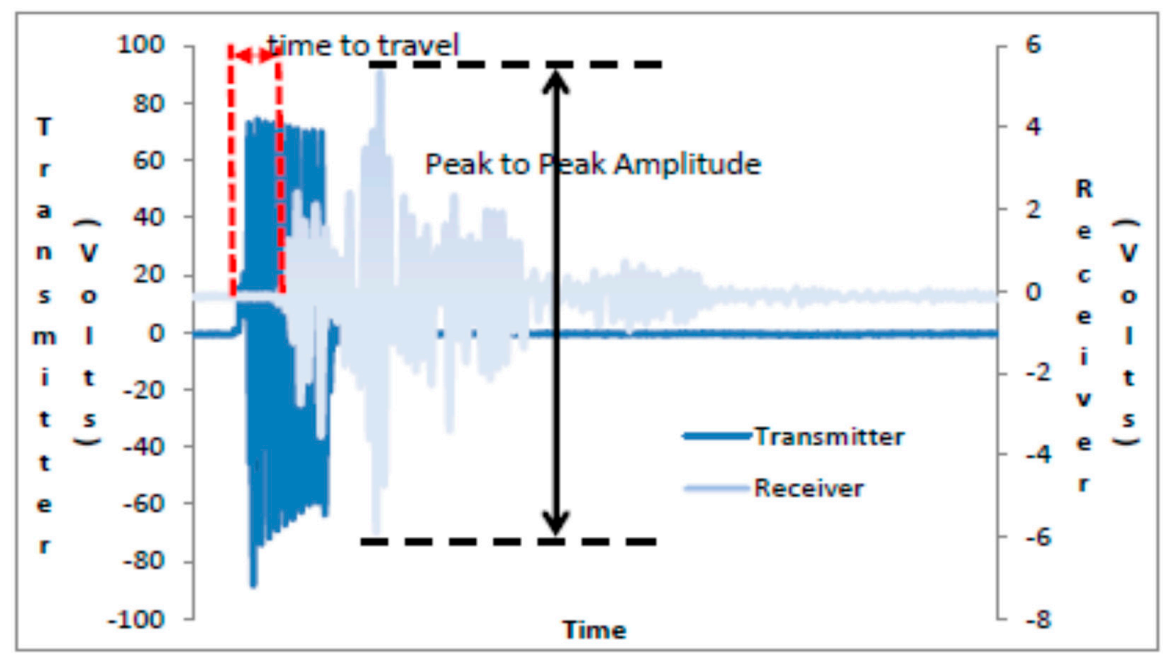

Figure 1. Linear ultrasonic test using ultrasonic pulse velocity (UPV) and peak to peak amplitude (PPA) in time-domain recorded from the transmitter and receiver.

On the material aspect, unreinforced concrete is sensitive to micro-cracking in the interfacial transition zone [17]. Variation of water-cement ratio proves to be a significant factor. It is found out that third harmonic ratio is sensitive compared to the second harmonic ratio [18]. In addition, second higher harmonic amplitude becomes large when crack opening displacement is small [19]. The sensitivity of the A2 and A3 depends on the type of loading introduced. For single loading pattern, A3 is sensitive compared to A2. On the other hand, in multiple step loading pattern A2 is sensitive to all water-cement ratio introduced [20]. It is also suggested that the amplifier is at high power level during experiments to produce better sensitivity in the generation of higher harmonics [21]. The amplitudes A1, A2, and A3 behaved similarly with PPA, where it is decreasing with respect to increasing load. A previous study shows that in concrete cubes, different loading patterns greatly influence the higher harmonics generation [20]. Complexity in its damage level is recognized when different sizes of aggregates inside the concrete are present [22].

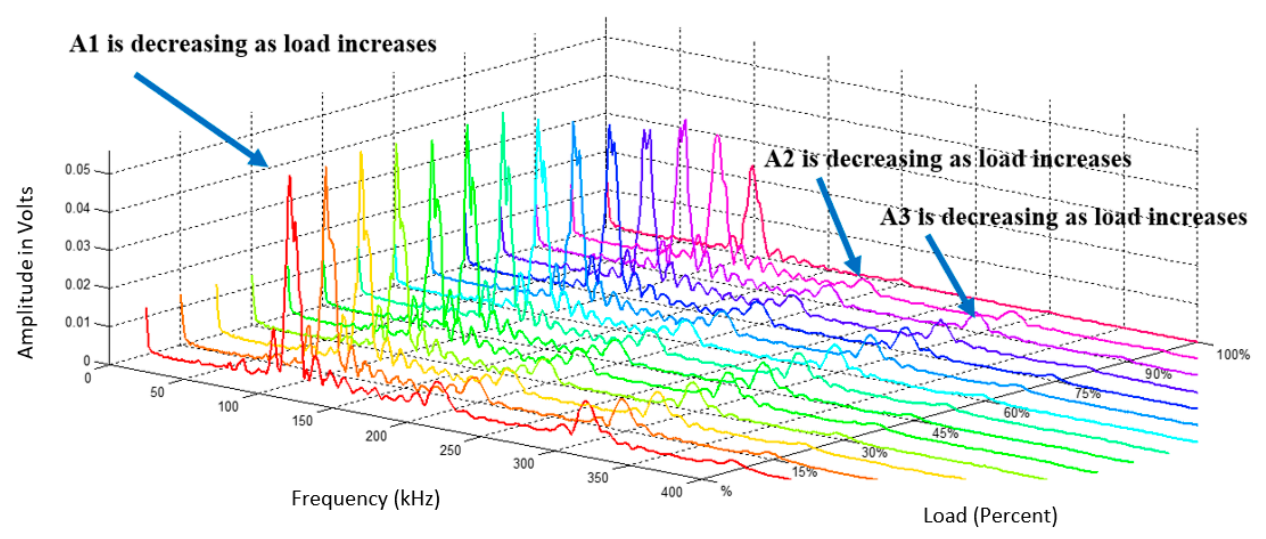

Figure 2. Nonlinear ultrasonic test using higher harmonic generations A1, A2, and A3 in frequency-domain recorded from the receiver (Ongpeng et al., 2016 [20]). 
There are limited papers investigating sensitivity of ultrasonic parameters in reinforced concrete beams. In this paper, time domain and frequency domain wave form were considered in a reinforced concrete beam under four-point bending test. The parameters for the sensitivity analysis were: fundamental harmonic amplitude (A1), second harmonic amplitude (A2), third harmonic amplitude (A3), and PPA. In addition, to investigate the strain developed in beams, neutral axis (NA) was considered to show the compression zone and tension zone of concrete during loading and unloading. These aforementioned parameters were used as input parameters to train, validate, and test the ANN models in coming up with an acceptable model using the highest Pearson's Correlation Coefficient $(R)$ and the soundness of the model when simulations were considered. The soundness of the model was an important factor since it will assure that the model was not overfitting despite of the high value of $R$ that may be present in models. Soundness of the model was verified using theories and findings from literatures (i.e., A2 should decrease when load is increasing).

\subsection{Artificial Neural Network in Structural Engineering and Materials}

ANN is a tool that is available in MATLAB 8.6 R2015b, the MathWorks, Inc., Natick, MA, USA. It is capable of modelling nonlinear systems that connect the input parameters with the output parameter. It is a tool for data mining that is based on the neural structure of the brain which can learn from experience or with training datasets. It consists of nodes having input layer, hidden layer and output layer. The nodes have initial weights and biases which when trained, will keep on updating as a part of training. The higher the weights, the higher the impact of the input node. It is used for modeling on prediction or estimation of strength of capacity of structures [23-36].

There are researches which focus on algorithm development like the study of decomposition techniques for multilayer perceptron training and surrogate models [37-39]. A fast and efficient method for training categorical radial basis function network is also studied [40]. From previous researches, it shows that ANN is desirable in attaining good models for the analysis of the experimental database available to explore the sensitivity of each parameters with load.

\subsection{Damage Assessment in Reinforced Concrete}

The damage detection becomes simple in some structures where system of homogenous materials is considered. As examples from literature, a model using ANN is used in structural health monitoring of curtain-wall system where mode of failure is clearly defined as total or partial destruction of its connections with the bearing structure [41]. In addition, a successful model identifying damages in sandwich composites by using Bayesian probabilistic neural network gave good agreement with the actual damage detection [42].

In contrast to homogenous materials, concrete is a very complex material. In modeling concrete, scale is introduced to limit the content of the defects. Three scales were introduced by Wittmann [43]: microscale, mesoscale, and macroscale. Microscale focuses on cement paste and aggregates where defects are crystal defects or atomic voids that are analyzed in material science models. Mesoscale considers unit cell with defects as microcracks and large pores that are studied using micromechanical models. Lastly, macroscale represents macrocrack defects where continuum and fracture mechanics theories can be applied. A previous study using mesoscale micromechanical damage model for concrete proposes kinetics of microcrack evolution [44]. The geometry of the model is characterized by the volume, random shape and disposition of aggregates. Another model using microplane for concrete focuses on the cracking localization [45]. This gives a good response on the quasi-brittle materials with a certain stress-strain boundary. A property of concrete that is significant to investigate is the vertex effect. This is when inelastic behavior of concrete for highly non-proportional loading paths leads to rotating principal stresses [46]. Some researches consider multiscale, i.e., a micro-to-macro damage scale, to initially investigate the natural behavior of materials when the test is applied. 
To further investigate reinforced concrete (RC), multiscale studies focused first on plain concrete. As an example, development of prediction models to investigate plain concrete using cylinder test results as training patterns in ANN gave good results. Two major techniques were applied to increase accuracy, these are parameter condensation and weighing technique [47]. In addition, data from laboratory tests using masonry clay bricks and cement mortar was also modeled using ANN and fuzzy logic to determine its compressive strength [48]. However, the addition of reinforcing bar greatly influenced the reinforced material behavior hence more research should be done.

Beam is an example of structural members in reinforced concrete. From study, artificial intelligence using ANN applied to reinforced concrete beams gave good agreement with the measurements to quantify and localize the damage or determine the damage patterns [49-53].

Reinforced concrete structures have different mode of failure. It can be classified as compression, flexure and shear where crack formations form depending on its failure mode. To investigate different structural members and its mode of failure, ANN were used in studies that showed good agreement with experimental tests [54-63].

In this paper, the mode of failure for the beam specimens was designed to be in flexure. No shear cracks were observed near support. The damage metrics used was the load percentage applied to the four-point bending test. Using the experimental database with five input parameters: A1, A2, A3, PPA, and NA, selection of optimum ANN model was done. The selection process had two criteria: highest $\mathrm{R}$ and soundness of the ANN model. Soundness of the ANN model was validated using simulations where A1, A2, A3, and PPA was decreasing with load, on the other hand, NA was increasing with load.

\subsection{Experimental Procedures}

Different types of reinforced concrete beam were introduced to relate the quantity of steel against the damage progression in terms of the load applied. A total of eighteen reinforced concrete beam specimens was produced. The size is $100 \mathrm{~mm} \times 100 \mathrm{~mm} \times 400 \mathrm{~mm}$ length with three reinforcement configurations. There were three beam specimens representing each type of design. The variations of design were as follows: three specimens for Design A with WC40, three specimens for Design A with WC60, three specimens for Design B with WC40, three specimens for Design B with WC60, three specimens for Design C with WC40, and three specimens for Design C with WC60. The sand-total aggregate ratio was $45 \%$ and shown in Table 1 was the design mix of the concrete. The reinforcing bar used for the stirrups and longitudinal bars were $9 \mathrm{~mm}$ diameter plain rounded steel bar with yield strength of $400 \mathrm{MPa}$. The reinforcement was designed into three types as shown in Figure 3. Beam design A has two longitudinal bars placed at the top and bottom with stirrups, beam design $B$ has two longitudinal bars placed at the bottom with stirrups, and beam design $C$ has only one longitudinal bar at the bottom without stirrups. Beams were designed where shear near the support would be insignificant, with an ultimate load of $22 \mathrm{kN}, 22 \mathrm{kN}$, and $12 \mathrm{kN}$ for designs A, B, and C, respectively. A pilot test was conducted to verify that the estimated ultimate load was experienced by the RC beams prior to the testing of $18 \mathrm{RC}$ beams. It was designed that shear near the support will be insignificant and will not be the cause of failure.

Table 1. Design mix of concrete.

\begin{tabular}{cccccc}
\hline \multirow{2}{*}{ Max. Aggregate Size (mm) } & \multicolumn{5}{c}{ Unit Quantity $\left(\mathbf{k g} / \mathbf{m}^{\mathbf{3}}\right)$} \\
\cline { 2 - 6 } & WC (\%) & Cement & Sand & Gravel & Water-Reducing Agent \\
\hline $20 \mathrm{~mm}$ & 40 & 344 & 761 & 1038 & 0.69 \\
$20 \mathrm{~mm}$ & 60 & 344 & 761 & 1038 & 0.69 \\
\hline
\end{tabular}

WC: water/cement ratio.

All the specimens were cured at 28th day with a universal testing machine to subject each specimen in a four-point bending test. Load diagram for the test is shown in Figure 4. Each loading and unloading pattern was classified into three repeated loading paths as Cycle 1 (0-20\% load), 
Cycle 2 (0-40\% load), Cycle 3 (0-60\% load), Cycle 4 (60-100\% load). This cyclic load was designed to explore the occurrence of repeated load similar to real structures. The influence of load history greatly affects ultrasonic parameters. As an example, A3 is sensitive to single loading path for pure concrete cubes [17], while A2 is more sensitive to a multiple loading paths [20].

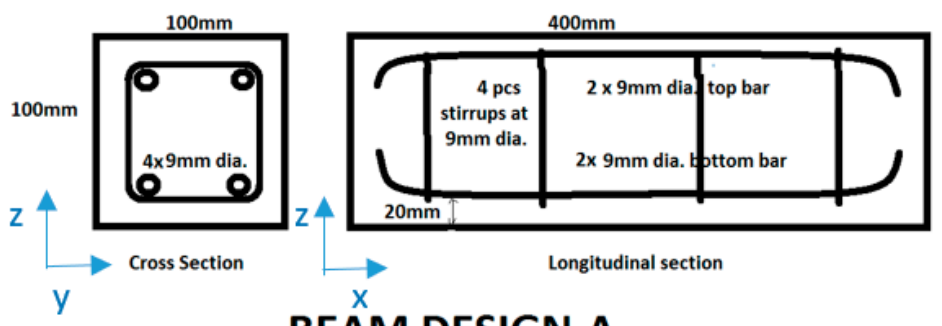

BEAM DESIGN A
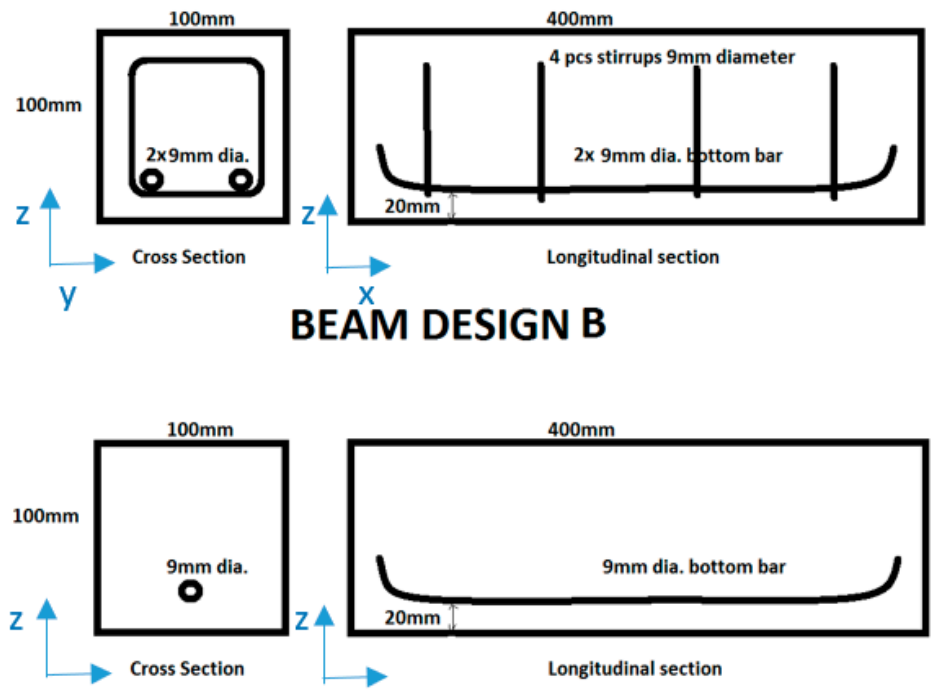

Figure 3. Reinforcements of the three beams (dimensions in $\mathrm{mm}$ ) pc: pieces.

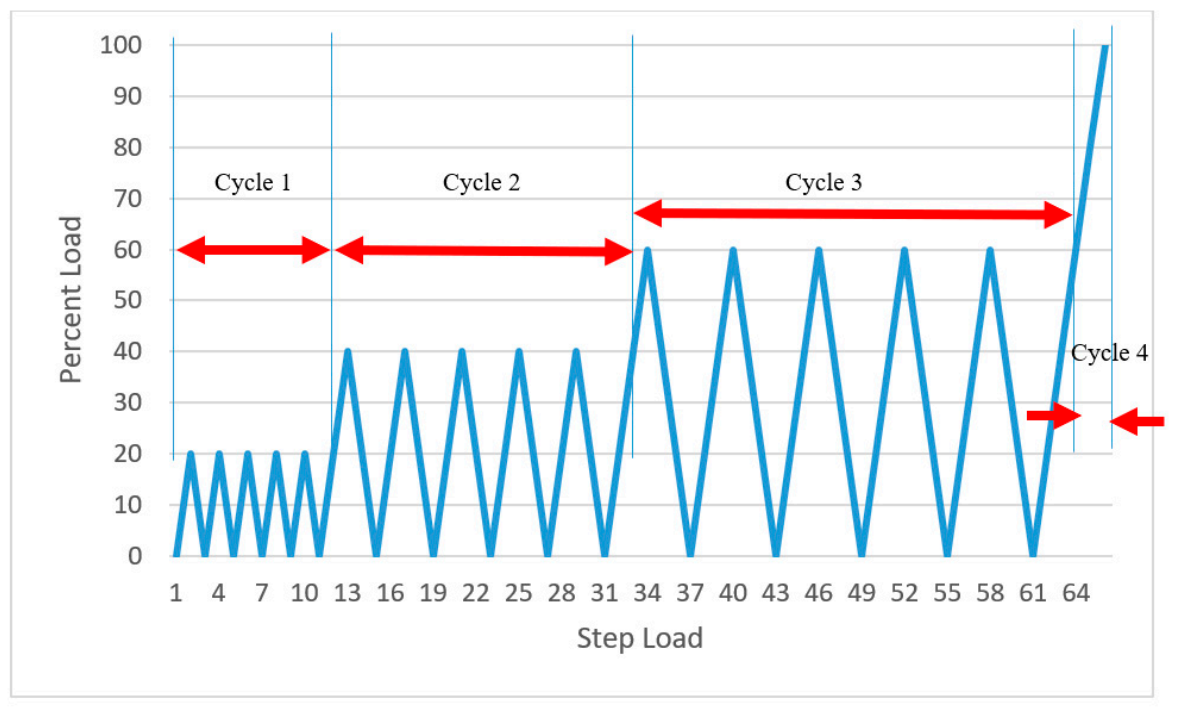

Figure 4. Step load for the four-point bending with loading/unloading branches. 
Ultrasonic testing was done in each step load with 68 data sets recorded for each beam. The transducers were oriented in direct transmission across the length of the beam. The experiment consisted of pulser with voltage equivalent to 1800 Volts aimed at single frequency which drove the nonlinear range response of the specimen. High gain broadband receiver was tuned to a desired frequency. This effectively eliminated the noise frequencies on the recorded datasets. It used low pass filter at $3 \mathrm{MHz}$ and high pass filter $50 \mathrm{kHz}$, and input impedance of $50 \Omega$. Transducers were carefully aligned and bonded to the concrete specimen using a gel-couplant on each end along the longitudinal direction with direct transmission. A transducer with $100 \mathrm{kHz}$ frequency was used to transmit the 10 cycles of sine wave tone burst signal through the beam with a receiver of $200 \mathrm{kHz}$ on the opposite end as shown in Figure 5.

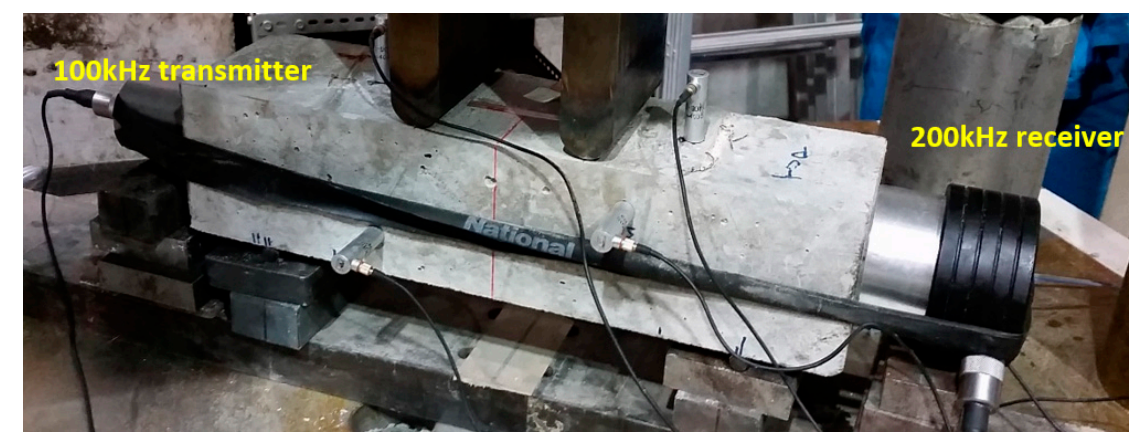

Figure 5. Ultrasonic and four-point bending test setup.

The reinforced concrete beam experiences both tension, resisted by the reinforcing bar, and compression, resisted by concrete. Another parameter is introduced to explore the behavior of the compression/tension zone. This parameter is NA which is considered to be promising in structural health monitoring as a sensitive universal parameter [64]. Two strain gauges are placed on horizontal surfaces along top and bottom of the concrete beam to measure its contraction or expansion against bending to determine the neutral axis.

The ANN modeling was done for each reinforcement design in each water-cement ratio. Each beam specimen has 68 data sets comprising of 5 input parameters (NA, A1, A2, A3, PPA) and one output (Load). The total number of data sets used for each ANN model derived was 3 specimen $\times 68$ data sets which is equal to 204 data sets.

Using the experimental results in the test, linear normalization of data was done for all the $18 \mathrm{RC}$ beam specimens. It converted all datasets to a minimum value of 0.0 and maximum value of 1.0 to eliminate the scaling of original data with small and large values. Shown in Figure 6 is a sample ANN model with 5 IN-3 HN-1 ON, where IN is the number of input parameters, $\mathrm{HN}$ is the number of hidden nodes, and ON is the number of output parameter. The ANN network architecture in this paper was defined as IN-HN-ON. The transfer function for each layer was varied, being L1 the first layer transfer function and L2 the second layer transfer function. In particular, LOGSIG and TANSIG were varied in L1 to obtain a model.

In the neural network, the 204 data sets per design were divided into $60 \%$ for training, $20 \%$ for validating and another $20 \%$ for testing. The training set was used in updating the weights and biases. The validation set was used to make sure that the network was generalizing and was used to stop the training of the network before overfitting occur. The testing set was used to measure on how good the model can generalize. The network training function used in this paper was Levenberg-Marquardt optimization where the target performance goal measured used mean square error. This function is one of the fastest backpropagation algorithms available. This algorithm was proven to give good results in the quality control for the resistance spot welding [65], prediction of the strength of mineral admixture concrete [66] and predicting residual strength of non-linear ultrasonic evaluated damaged concrete [8]. 
The ANN network when trained, validated, and tested to attain a performance goal produced stochastic results. Each run of the model produced unique weights and biases that were saved for further analysis.

The number of hidden nodes were varied from 3, 4, 5, 6 and 11 to come up with sixty distinct ANN models. The transfer function was varied for the first layer using hyperbolic tangent sigmoid function (TANSIG) and log-sigmoid transfer function (LOGSIG), while the second layer transfer function was linear transfer function (PURELIN). Single inner layer was used throughout the modeling to arrive at the simplest model in predicting the damage in terms of load. A previous study gave good estimate of the number of hidden nodes needed [67].

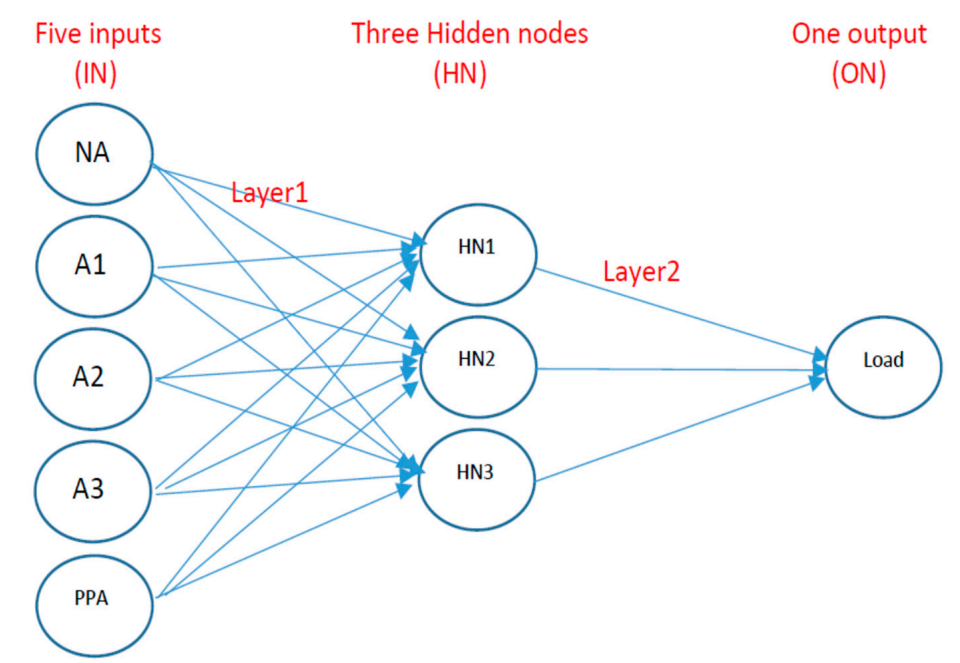

Figure 6. Artificial neural network (ANN) model with 5 IN-3 HN-1 ON with layer 1 (L1) and layer 2 (L2) as transfer functions.

\section{Results and Discussion}

Pilot testing for plain concrete cubes of $150 \mathrm{~mm}$ size $[5,20,22]$ and reinforced concrete beams were done in the laboratory to ensure that the nonlinearities or the presence of higher harmonics resulted from the material nonlinear response due to mechanical damage and not from the instrumentation used in the test.

Shown in Figure 7 is the experimental result of WC60C specimen one where A3 and load is investigated. In addition, shown in Figure 8 is the result from WC60C specimen three. It showed that A2 and the applied load shows good agreement with each other. Experimental results show that the analysis of data using statistical method to model the behavior is very complex and ANN modeling is advantageous to classify sensitivity of parameters with load.

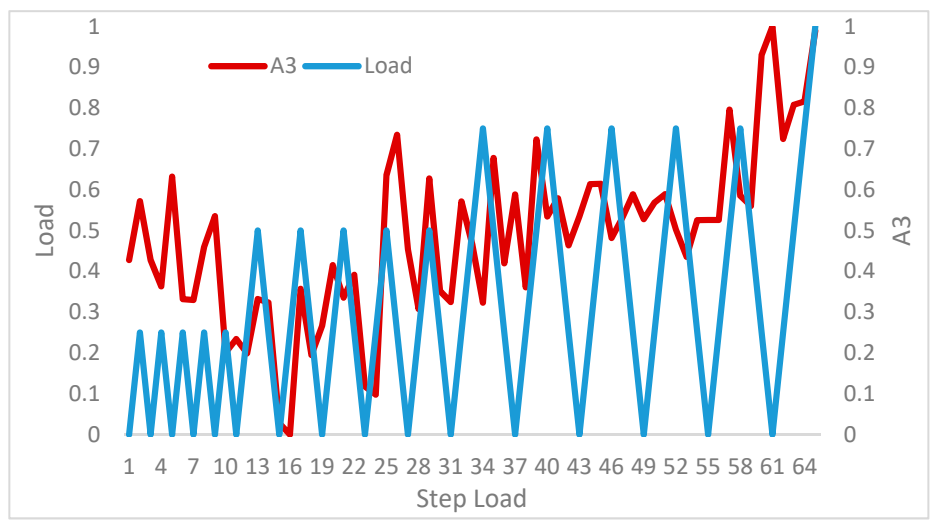

Figure 7. WC60C Specimen one: A3 versus load. 


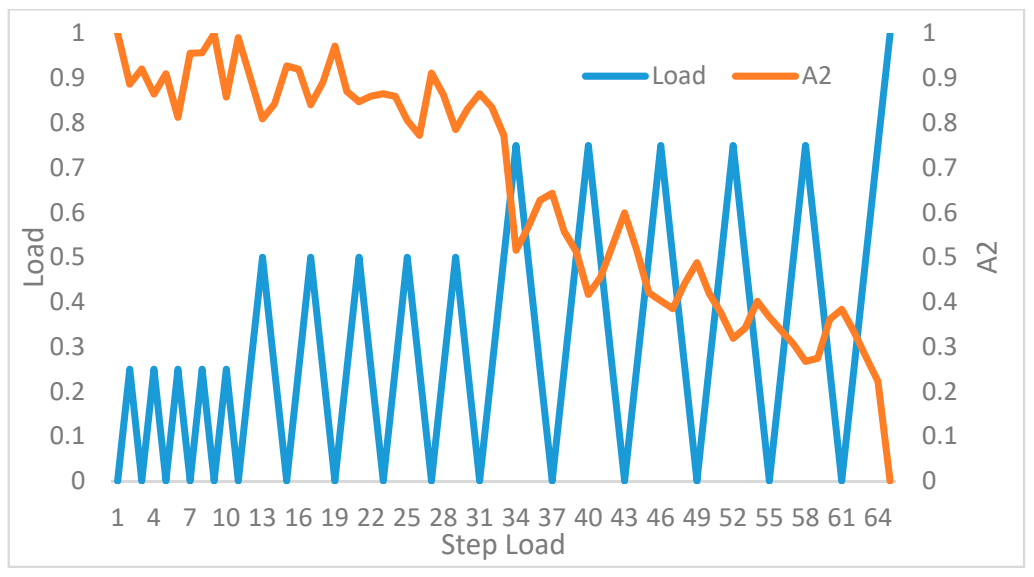

Figure 8. WC60C Specimen three: A2 versus load.

The last parameter used for ANN modelling is NA. In determining the neutral axis location with respect to load, the recorded tensile and compressive strain is considered at the mid span of the beam. Cross-section of the sample strain diagram at a particular step load and its corresponding stress diagram is shown in Figure 9. The stress at the top fiber of the concrete is assumed to have a maximum value of 0.85 of ultimate confined compressive strength ( $\left.\mathrm{fc}^{\prime}\right)$ in MegaPascal for SI units. This location of neutral axis is dynamic due to the changes in elongation or contraction at the top and bottom of the beam during the step loads in the experiment. It is computed using Equation (2). Location of neutral axis $y$ is based on the theory on elastic on elastic design of reinforced concrete. The distance NA is shown in Figure 9 based from the mid height of the cross section of the beam to the neutral axis for a particular load. Seen in Figure 10 is the behaviour of the neutral axis for WC40C Specimen three with load. It shows that the relationship of NA with load is complex.

$$
y=\varepsilon_{\mathcal{C}}(\mathrm{h}) /\left(\varepsilon_{t}-\varepsilon_{\mathcal{c}}\right)
$$

where: $\varepsilon_{c}$-average strain at midpoint of the top surface in compression, $\varepsilon_{t}$-average strain at midpoint bottom surface in tension, $\mathrm{h}$ - height of the beam.

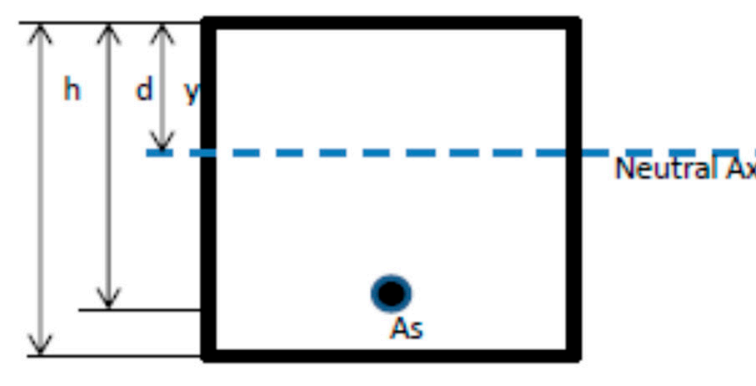

b

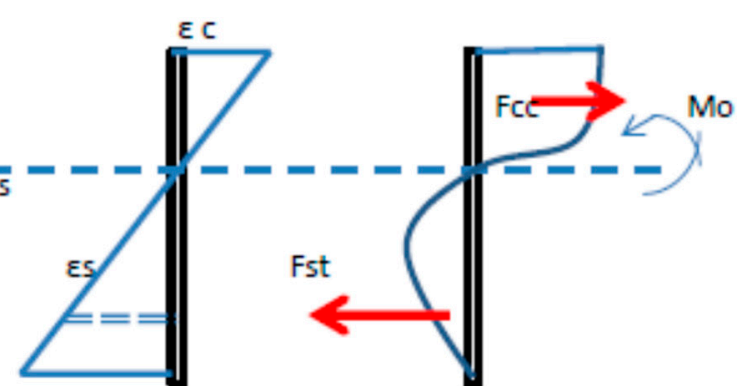

$\varepsilon t$

(B)

(C)

Figure 9. Neutral axis across (A) cross section of the beam; (B) strain diagram; (C) stress diagram. NA: neutral axis.

From the 60 ANN models trained, validated, and tested, a model was chosen for each WC corresponding to each reinforcement design having the highest Pearson correlation coefficient $(R)$ in testing, and the soundness of the behavior for the input parameters in relation to the damage in concrete in terms of load. Some of the models had its $R=0.98$, but models may tend to overfit. The soundness of models was checked by having simulations attuned to theory to avoid overfitting. As an example, 
decreasing PPA led to increasing compressive stress or increasing load. In this way, it prevented the trained ANN models to overfit even if it had the most desirable $R$. Shown in Tables 2 and 3 are the ANN models $R$, for the training, validating, and testing data.

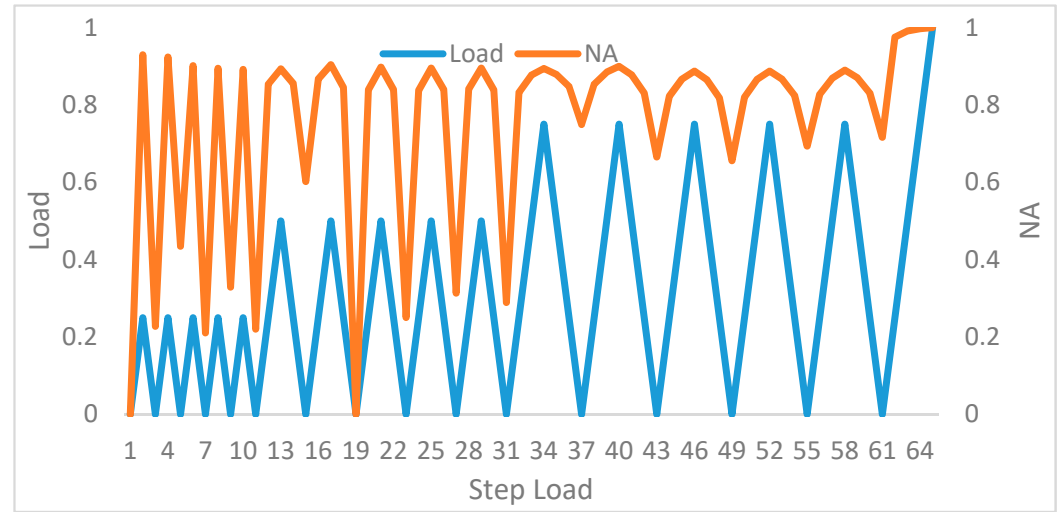

Figure 10. WC40C Specimen three: NA versus load.

Table 2. Trained, validated, and tested ANN models for WC40 concrete.

\begin{tabular}{|c|c|c|c|c|c|c|}
\hline \multirow[b]{2}{*}{ Design } & \multirow[b]{2}{*}{ X (Varying HN) } & \multirow[b]{2}{*}{ L1 } & \multirow[b]{2}{*}{$\mathbf{L} 2$} & \multicolumn{3}{|c|}{ Pearson Correlation Coefficient $(R)$} \\
\hline & & & & $\begin{array}{c}\text { Training } \\
\text { Data }\end{array}$ & $\begin{array}{c}\text { Validating } \\
\text { Data }\end{array}$ & $\begin{array}{c}\text { Testing } \\
\text { Data }\end{array}$ \\
\hline \multirow{10}{*}{ A } & 3 & \multirow{5}{*}{ LOGSIG } & \multirow{5}{*}{ PURELIN } & 0.89 & 0.88 & 0.91 \\
\hline & 4 & & & 0.90 & 0.81 & 0.88 \\
\hline & 5 & & & 0.92 & 0.91 & 0.88 \\
\hline & 6 & & & 0.90 & 0.90 & 0.93 \\
\hline & 11 & & & 0.90 & 0.92 & 0.88 \\
\hline & 3 & \multirow{5}{*}{ TANSIG } & \multirow{5}{*}{ PURELIN } & 0.89 & 0.83 & 0.93 \\
\hline & 4 & & & 0.89 & 0.79 & 0.89 \\
\hline & 5 & & & 0.89 & 0.84 & 0.91 \\
\hline & 6 & & & 0.92 & 0.84 & 0.88 \\
\hline & 11 & & & 0.91 & 0.90 & 0.91 \\
\hline \multirow{10}{*}{$\mathrm{B}$} & 3 & \multirow{5}{*}{ LOGSIG } & \multirow{5}{*}{ PURELIN } & 0.82 & 0.83 & 0.76 \\
\hline & 4 & & & 0.88 & 0.73 & 0.90 \\
\hline & 5 & & & 0.84 & 0.89 & 0.90 \\
\hline & 6 & & & 0.87 & 0.81 & 0.89 \\
\hline & 11 & & & 0.87 & 0.93 & 0.92 \\
\hline & 3 & \multirow{5}{*}{ TANSIG } & \multirow{5}{*}{ PURELIN } & 0.80 & 0.84 & 0.84 \\
\hline & 4 & & & 0.86 & 0.85 & 0.83 \\
\hline & 5 & & & 0.82 & 0.89 & 0.87 \\
\hline & 6 & & & 0.85 & 0.73 & 0.83 \\
\hline & 11 & & & 0.87 & 0.95 & 0.80 \\
\hline \multirow{10}{*}{$\mathrm{C}$} & 3 & \multirow{5}{*}{ LOGSIG } & \multirow{5}{*}{ PURELIN } & 0.61 & 0.67 & 0.68 \\
\hline & 4 & & & 0.70 & 0.71 & 0.59 \\
\hline & 5 & & & 0.63 & 0.74 & 0.77 \\
\hline & 6 & & & 0.70 & 0.84 & 0.55 \\
\hline & 11 & & & 0.70 & 0.87 & 0.87 \\
\hline & 3 & \multirow{5}{*}{ TANSIG } & \multirow{5}{*}{ PURELIN } & 0.64 & 0.71 & 0.46 \\
\hline & 4 & & & 0.63 & 0.82 & 0.73 \\
\hline & 5 & & & 0.73 & 0.72 & 0.64 \\
\hline & 6 & & & 0.72 & 0.75 & 0.72 \\
\hline & 11 & & & 0.75 & 0.87 & 0.92 \\
\hline
\end{tabular}

There were six optimum ANN models highlighted and taken from Tables 2 and 3. Selection of the optimum models were considered with two criteria, highest $R$ in testing data and model that gave a sound simulation according to theories and literature. For WC40A, B and C, the ANN models 
were $5 \mathrm{IN}-6 \mathrm{HN}-1 \mathrm{ON}, 5 \mathrm{IN}-11 \mathrm{HN}-1 \mathrm{ON}$, and $5 \mathrm{IN}-5 \mathrm{HN}-1 \mathrm{ON}$, respectively. On the other hand, WC60A, $B$ and $C$ had optimum ANN models as $5 \mathrm{IN}-11 \mathrm{HN}-1 \mathrm{ON}, 5 \mathrm{IN}-11 \mathrm{HN}-1 \mathrm{ON}$, and $5 \mathrm{IN}-11 \mathrm{HN}-1 \mathrm{ON}$, respectively. It was noted that some of the trained and tested models gave $R$ values less than 0.50 which was considered very low and poor in performance. These were attributed by complex relationships of input and output parameters with the use of simple ANN structures comprising of one hidden layer only. It was recommended to further investigate and explore the use of ANN structures with deep learning or with large number of hidden layers to prevent low or poor performing models from the selection list of available models.

After selection of optimum model, amplitude sensitivity analysis was introduced as shown in Equation (3) for PPA, A1, A2, and A3 [3]. This was used to analyze the behavior of the amplitude when it decreased with an increasing load. On the other hand, the NA sensitivity analysis showed opposite behavior compared to the behaviors of the four parameters mentioned. Equation (4) was used for NA which increased when also the load increased.

$$
\begin{gathered}
D a=1-f(x) / f \max \\
D a=f(x) / f \max
\end{gathered}
$$

where: $D a$ : Sensitivity of parameter to load; $f(x)$ : Value of the parameter; fmax: Maximum value of the same parameter $f(x)$.

Sensitivity is difficult to measure. In this paper, simulation of optimum ANN models is carried out and classification of sensitivity to four groups is made as shown in Table 4. These groups are: Long range sensitivity (LRS), Short range sensitivity (SRS), Insensitive to load (IL), and Insensitive to parameter (IP). Shown in Figure 11 is the simulation of the three optimum models for WC60A, B and $\mathrm{C}$ where $\mathrm{A} 3$ is varied while the four parameters are constant at 0.5 . Sensitivity classification of WC60A, $\mathrm{B}$ and $\mathrm{C}$ in Figure 11 shows that WC60A is classified as LRS, WC60B as SRS, WC60C as IL.

\begin{tabular}{|c|c|c|c|c|c|c|}
\hline \multirow[b]{2}{*}{ Design } & \multirow[b]{2}{*}{ X (Varying HN) } & \multirow[b]{2}{*}{ L1 } & \multirow[b]{2}{*}{ L2 } & \multicolumn{3}{|c|}{ Pearson Correlation Coefficient $(R)$} \\
\hline & & & & $\begin{array}{c}\text { Training } \\
\text { Data }\end{array}$ & $\begin{array}{c}\text { Validating } \\
\text { Data }\end{array}$ & $\begin{array}{c}\text { Testing } \\
\text { Data }\end{array}$ \\
\hline \multirow{10}{*}{ A } & 3 & \multirow{5}{*}{ LOGSIG } & \multirow{5}{*}{ PURELIN } & 0.67 & 0.70 & 0.70 \\
\hline & 4 & & & 0.71 & 0.77 & 0.67 \\
\hline & 5 & & & 0.64 & 0.65 & 0.82 \\
\hline & 6 & & & 0.71 & 0.53 & 0.74 \\
\hline & 11 & & & 0.62 & 0.61 & 0.50 \\
\hline & 3 & \multirow{5}{*}{ TANSIG } & \multirow{5}{*}{ PURELIN } & 0.66 & 0.67 & 0.56 \\
\hline & 4 & & & 0.65 & 0.65 & 0.68 \\
\hline & 5 & & & 0.70 & 0.75 & 0.70 \\
\hline & 6 & & & 0.48 & 0.79 & 0.64 \\
\hline & 11 & & & 0.70 & 0.72 & 0.82 \\
\hline \multirow{10}{*}{ B } & 3 & \multirow{5}{*}{ LOGSIG } & \multirow{5}{*}{ PURELIN } & 0.73 & 0.52 & 0.86 \\
\hline & 4 & & & 0.77 & 0.79 & 0.74 \\
\hline & 5 & & & 0.72 & 0.91 & 0.86 \\
\hline & 6 & & & 0.76 & 0.69 & 0.74 \\
\hline & 11 & & & 0.77 & 0.66 & 0.89 \\
\hline & 3 & \multirow{5}{*}{ TANSIG } & \multirow{5}{*}{ PURELIN } & 0.70 & 0.65 & 0.50 \\
\hline & 4 & & & 0.78 & 0.76 & 0.77 \\
\hline & 5 & & & 0.73 & 0.83 & 0.81 \\
\hline & 6 & & & 0.75 & 0.70 & 0.86 \\
\hline & 11 & & & 0.74 & 0.83 & 0.85 \\
\hline
\end{tabular}

Table 3. Trained, validated, and tested ANN models for WC60 concrete. 
Table 3. Cont.

\begin{tabular}{|c|c|c|c|c|c|c|}
\hline \multirow[b]{2}{*}{ Design } & \multirow[b]{2}{*}{ X (Varying HN) } & \multirow[b]{2}{*}{ L1 } & \multirow[b]{2}{*}{ L2 } & \multicolumn{3}{|c|}{ Pearson Correlation Coefficient $(R)$} \\
\hline & & & & $\begin{array}{c}\text { Training } \\
\text { Data }\end{array}$ & $\begin{array}{c}\text { Validating } \\
\text { Data }\end{array}$ & $\begin{array}{c}\text { Testing } \\
\text { Data }\end{array}$ \\
\hline \multirow{10}{*}{$\mathrm{C}$} & 3 & \multirow{5}{*}{ LOGSIG } & \multirow{5}{*}{ PURELIN } & 0.49 & 0.45 & 0.38 \\
\hline & 4 & & & 0.50 & 0.44 & 0.57 \\
\hline & 5 & & & 0.58 & 0.50 & 0.62 \\
\hline & 6 & & & 0.52 & 0.67 & 0.69 \\
\hline & 11 & & & 0.59 & 0.32 & 0.72 \\
\hline & 3 & \multirow{5}{*}{ TANSIG } & \multirow{5}{*}{ PURELIN } & 0.49 & 0.40 & 0.53 \\
\hline & 4 & & & 0.42 & 0.59 & 0.44 \\
\hline & 5 & & & 0.55 & 0.48 & 0.42 \\
\hline & 6 & & & 0.56 & 0.59 & 0.57 \\
\hline & 11 & & & 0.48 & 0.55 & 0.59 \\
\hline
\end{tabular}

Table 4. Classification of sensitivity during simulation of optimum ANN models.

\begin{tabular}{ccc}
\hline Classification of Sensitivity & Average Angle of Tangent Line ( $\beta$ ) & Range (L) \\
\hline Long range sensitive (LRS) & $10^{\circ} \leq \beta \leq 80^{\circ}$ & $\geq 20 \%$ load \\
Short range sensitive (SRS) & $10^{\circ} \leq \beta \leq 80^{\circ}$ & $<20 \%$ load \\
Insensitive to load (IL) & $\beta>80^{\circ}$ & $<20 \%$ load \\
Insensitive to parameter (IP) & $\beta<10^{\circ}$ & $<20 \%$ load \\
\hline
\end{tabular}

To further investigate the sensitivity of all parameters with increasing load, simulations are done for all five variable parameters having the other four input parameters as constant ( 0.5 in value). Shown in Figure 12 is the behavior of the sensitivity of each parameter with load. Some graphs did not start at the origin since the simulation of the optimum ANN models are trained, validated and tested with datasets known to the optimum ANN model. The ANN model cannot extrapolate from its datasets, hence there is a boundary limit on the simulation results. Seen in Table 5 is the summary of sensitivity classifications after investigating Figure 12. It shows A2 and NA have good sensitivity for any WC content and any reinforcing bar content. However, this sensitivity may be of short or long range. For WC40A and B, parameters insensitive to load were A1 and PPA, respectively. The parameter A3 is not sensitive to load for WC60C where concrete without reinforcing bars are experienced. This is also experienced by WC60 with repeated load where A3 became insensitive while A2 is sensitive [18-20].

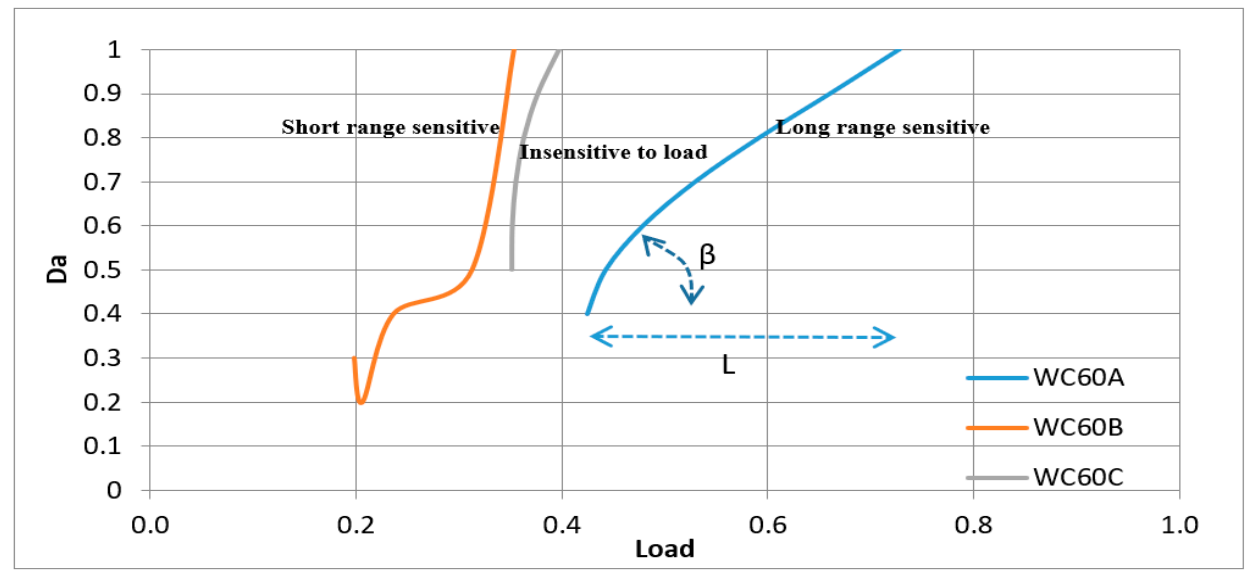

Figure 11. Sensitivity of parameter (Da) A3 for WC60A, B and C from the ANN simulation. 
Table 5. Classification of sensitivity for all parameters simulated from optimum ANN models.

\begin{tabular}{ccccccc}
\hline Parameters & WC40A & WC40B & WC40C & WC60A & WC60B & WC60C \\
\hline PPA & SRS & IL & LRS & LRS & SRS & SRS \\
A1 & IL & LRS & LRS & LRS & LRS & LRS \\
A2 & SRS & LRS & LRS & SRS & SRS & LRS \\
A3 & SRS & LRS & LRS & LRS & SRS & IL \\
NA & LRS & LRS & SRS & LRS & LRS & SRS \\
\hline
\end{tabular}

Yellow-indicates good sensitivity and can detect damage more than $20 \%$. White-indicates good sensitivity and can only detect damage for less than $20 \%$. Red-indicates poor sensitivity and cannot detect damage.

PPA

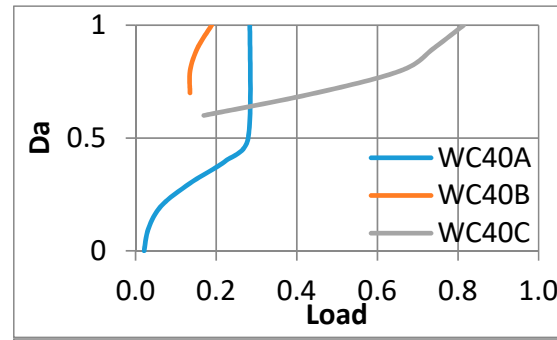

A1

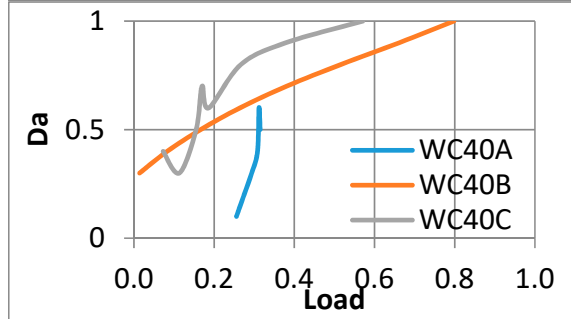

A2

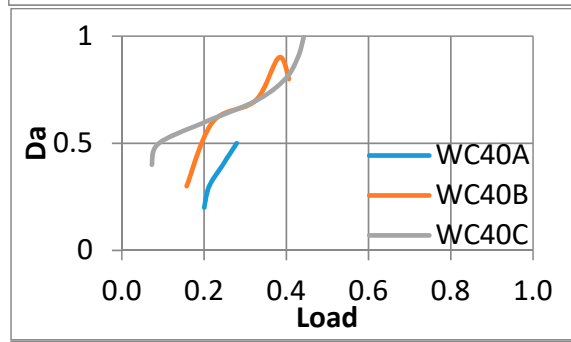

A3
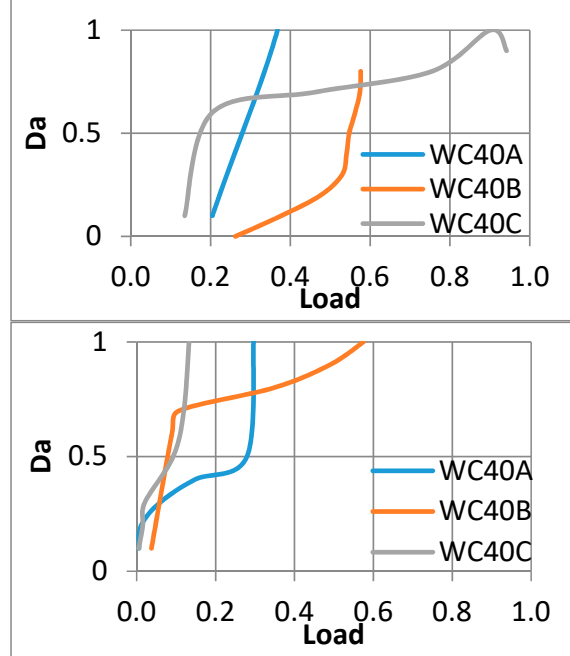
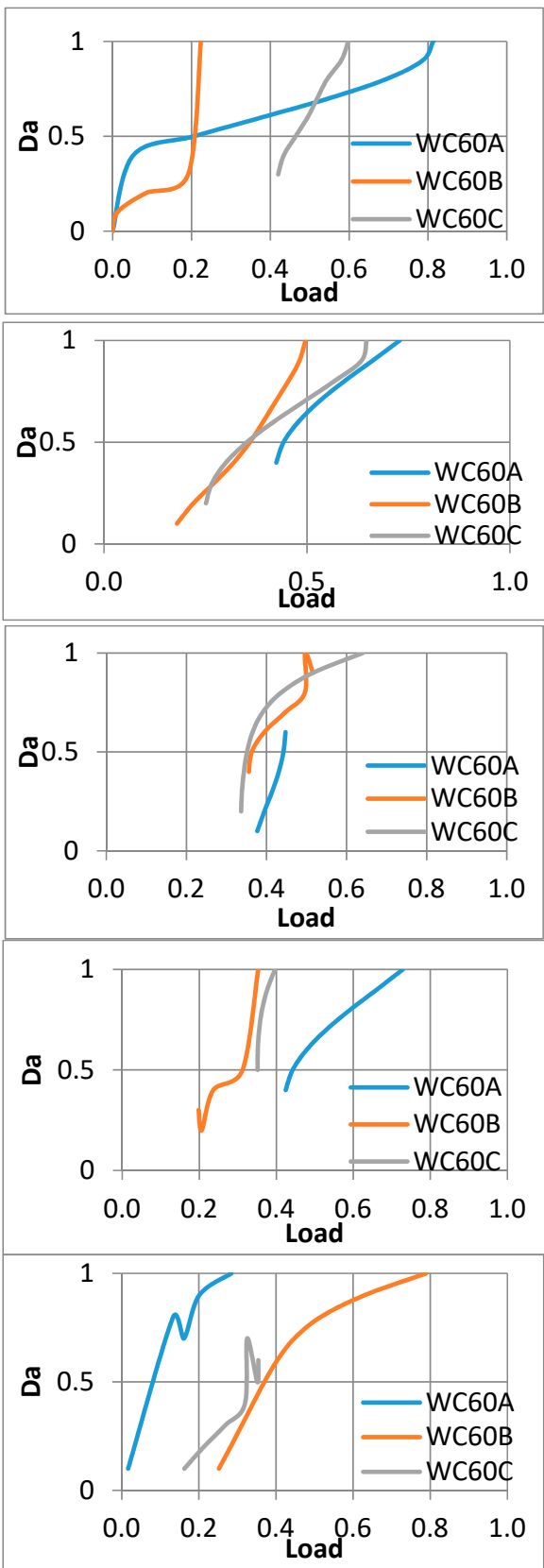

Figure 12. Sensitivity of all parameters simulated from optimum ANN models. 


\section{Conclusions}

This paper used experimental results from ultrasonic test with varying WC and reinforcing bars tested under four-point bending test. ANN was used to train, validate, and test models using five input parameters fundamental harmonic amplitude A1, second harmonic amplitude A2, third harmonic amplitude A3, PPA, and NA in predicting the percentage of ultimate load it experienced. Specifically, classification of sensitivity as short range (less than $20 \%$ of damage) and long range (more than $20 \%$ of damage) was done from ANN simulation derived from optimum ANN models. It was found out that $\mathrm{A} 2$ and NA proved to be sensitive for all WC and reinforcing bar content. It showed that the range of sensitivity of A2 increased when reinforcing bar decreased, while the range of sensitivity of NA decreased when reinforcing bar decreased. These two parameters showed good agreement with the load applied to the reinforced concrete beam.

This study can be used as a guide in the selection of ultrasonic parameters to assess damage for concrete with low or high WC and with varying reinforcement.

Acknowledgments: The research work was funded under the JSPS-Ronpaku Scholarship. The open access publication fee was funded by J.M.C.O., the main author.

Author Contributions: J.M.C.O., A.W.C.O. and S.H. conceived and designed the experiments; J.M.C.O. performed the experiments, analyzed the data, and wrote the paper.

Conflicts of Interest: The authors declare no conflict of interest.

\section{Nomenclature}

$\begin{array}{ll}\text { Acronym/Symbol } & \text { Description } \\ \text { ANN } & \text { Artificial Neural Network } \\ \text { WC } & \text { Water-Cement Ratio } \\ \text { design A } & \text { Two longitudinal top bars and two longitudinal bottom bars } \\ \text { design B } & \text { Two longitudinal bottom bars } \\ \text { design C } & \text { One longitudinal bottom bar } \\ \text { NA } & \text { Neutral Axis } \\ \text { A1 } & \text { Fundamental Harmonic Amplitude } \\ \text { A2 } & \text { second Harmonic Amplitude } \\ \text { A3 } & \text { Third Harmonic Amplitude } \\ \text { PPA } & \text { Peak to Peak Amplitude in Time Domain } \\ R & \text { Pearson's Correlation Coefficient } \\ \text { Cycle } 1 & \text { Cyclic load from } 0 \text { to } 20 \% \text { of ultimate load } \\ \text { Cycle 2 } & \text { Cyclic load from 0 to } 40 \% \text { of ultimate load } \\ \text { Cycle } 3 & \text { Cyclic load from } 0 \text { to } 60 \% \text { of ultimate load } \\ \text { Cycle } 4 & \text { Load from } 60 \text { to } 100 \% \text { of ultimate load } \\ \text { IN } & \text { Input parameters of ANN } \\ \text { X HN } & \text { Hidden nodes of ANN } \\ \text { ON } & \text { Output parameter of ANN } \\ \text { SRS } & \text { Short range sensitivity (less than 20\% load) } \\ \text { LRS } & \text { Long range sensitivity (more than 20\% load) } \\ \text { IP } & \text { Insensitive to parameter } \\ \text { IL } & \text { Insensitive to load } \\ \text { L1 } & \text { 1st layer transfer function } \\ \text { L2 } & \text { second layer transfer function } \\ D a & \text { Sensitivity of parameter to load } \\ f(x) & \text { Value of the parameter } \\ F m a x & \text { Maximum value of the parameter } \\ y & \text { Neutral axis distance from top fiber } \\ \varepsilon_{\mathcal{C}} & \text { Average strain at midpoint top surface in compression } \\ \varepsilon_{t} & \text { Average strain at midpoint bottom surface in tension } \\ h & \text { Height of the beam } \\ & \end{array}$




\section{References}

1. Ongpeng, J.; Oreta, A.; Hirose, S. Damage Progression in Concrete using Acoustic Emission Test through Convex Hull Visualization. ACI Mater. 2016, 113, 737-744. [CrossRef]

2. Ongpeng, J. Acoustic Emission Test in Visualizing Crack Progression for Concrete Beams. Asian J. Civ. Eng. 2016, 17, 479-486.

3. Ongpeng, J.; Oreta, A.; Hirose, S. Monitoring Damage Using Acoustic Emission Source Location and Computational Geometry in Reinforced Concrete Beams. Appl. Sci. 2018, 8, 189. [CrossRef]

4. Ongpeng, J. Ultrasonic Pulse Velocity Test of Reinforced Concrete with Induced Corrosion. ASEAN Eng. J. Part C 2017, 6, 5-12.

5. Ongpeng, J.; Soberano, M.; Oreta, A.; Hirose, S. Artificial Neural Network Model using Ultrasonic Test Results to Predict Compressive Stress in Concrete. Comput. Concr. 2017, 19, 59-68. [CrossRef]

6. Komlos, K.; Popovics, S.; Nurnbergerova, T.; Babal, B.; Popovics, J.S. Ultrasonic pulse velocity test of concrete properties as specified in various standards. Cem. Concr. Compos. 1996, 18, 357-364. [CrossRef]

7. Shah, A.A.; Ribakov, Y. Non-linear non-destructive evaluation of concrete. Constr. Build. Technol. J. 2008, 2, 111-115. [CrossRef]

8. Shah, A.; Alsayed, S.; Abbas, H.; Al-Salloum, Y. Predicting residual strength of non-linear ultrasonically evaluated damaged concrete using artificial neural network. Constr. Build. Mater. 2012, 20, 42-50. [CrossRef]

9. Zheng, Y.; Maev, R.G.; Solodov, I.Y. Nonlinear acoustic applications for material characterization: A review. Can. J. Phys. 1999, 77, 927-967. [CrossRef]

10. Solodov, I.Y.; Krohn, N.; Busse, G. CAN: An example of nonclassical acoustic nonlinearity in solids. Ultrasonics 2002, 40, 621-625. [CrossRef]

11. Korshak, B.A.; Solodov, I.Y.; Ballad, E.M. DC effects, sub-harmonics, stochasticity and "memory" for contact acoustic nonlinearity. Ultrasonics 2002, 40, 707-713. [CrossRef]

12. Solodov, I.Y. Ultrasonics of nonlinear contacts: Propagations, reflection and NDE-applications. Ultrasonics 1998, 36, 383-390. [CrossRef]

13. Solodov, I.Y.; Doring, D.; Busse, G. New opportunities for NDT using non-linear interaction of elastic waves with defects. J. Mech. Eng. 2011, 57, 169-182. [CrossRef]

14. Solodov, I.Y.; Chin, A.W. Popping Nonlinearity and Chaos in Vibrations of Contact Interface between Solids. Acoust. Phys. 1993, 39, 476-479.

15. Yim, H.J.; Kim, J.H.; Park, S.J.; Kwak, H.G. Characterization of thermally damaged concrete using non-linear ultrasonic method. Cem. Concr. Res. 2012, 42, 1438-1446. [CrossRef]

16. Shah, A.A.; Hirose, S. Nonlinear ultrasonic investigation of concrete damaged under uniaxial compression step loading. J. Mater. Civ. Eng. 2010, 22, 476-484. [CrossRef]

17. Shah, A.A.; Ribakov, Y. Non-linear ultrasonic evaluation of damaged concrete based on higher order harmonic generation. Mater. Des. 2009, 30, 4095-4102. [CrossRef]

18. Shah, A.A.; Ribakov, Y.; Hirose, S. Nondestructive evaluation of damaged concrete using non-linear ultrasonics. Mater. Des. 2009, 30, 775-782. [CrossRef]

19. Hirose, S.; Achenbach, J.D. Higher harmonics in the far field due to dynamic crack-face contacting. J. Acoust. Soc. Am. 1993, 93, 142-147. [CrossRef]

20. Ongpeng, J.M.C.; Oreta, A.W.C.; Hirose, S. Effect of load pattern in the generation of higher harmonic amplitude in concrete using nonlinear ultrasonic test. J. Adv. Concr. Technol. 2016, 14, 205-214. [CrossRef]

21. Shah, A.A.; Ribakov, Y.; Zhang, C. Efficiency and sensitivity of linear and non-linear ultrasonics to identifying micro- and macro-scale defects in concrete. Mater. Des. 2013, 50, 905-916. [CrossRef]

22. Ongpeng, J.M.C.; Oreta, A.W.C.; Hirose, S.; Nakahata, K. Nonlinear ultrasonic investigation of concrete with varying aggregate size under uniaxial compression loading and unloading. J. Mater. Civ. Eng. 2017. [CrossRef]

23. Demir, A. Prediction of hybrid fibre-added concrete strength using artifical neural networks. Comput. Concr. 2015, 15, 503-514. [CrossRef]

24. Oreta, A.; Ongpeng, J. Modeling the confined compressive strength of hybrid circular concrete columns using neural networks. Comput. Concr. 2011, 8, 597-616. [CrossRef] 
25. Alexandridis, A.; Stravrakas, I.; Stergiopoulos, C.; Hloupis, G.; Ninos, K.; Triantis, D. Non-destructive assessment of the three-point-bending strength of mortar beams using radial basis functionneural networks. Comput. Concr. 2015, 16, 919-932. [CrossRef]

26. Bilgehan, M.; Turgut, P. The use of artificial neural network in concrete compressive strength estimation. Comput. Concr. 2010, 7, 271-283. [CrossRef]

27. Jiang, B.; Zhao, W.; Wang, W. Improved ultrasonic computerized tomography method for STS (Steel Tube Slab) structure based on compressive sampling algorithm. Appl. Sci. 2017, 7, 432. [CrossRef]

28. Suleiman, A.R.; Nehdi, M.L. Modeling self-healing of concrete using hybrid genetic algorithm-artificial neural network. Appl. Sci. 2017, 10, 135. [CrossRef] [PubMed]

29. De Felippis, L.A.; Serio, L.M.; Facchini, F.; Mummolo, G.; Ludovico, A.D. Prediction of the Vickers microhardness and ultimate tensile strength of AA5754 H111 friction stir welding butt joints using artificial neural network. Materials 2016, 9, 915. [CrossRef] [PubMed]

30. Zhang, W.; Bao, Z.; Jiang, S.; He, J. An artificial neural network-based algorithm for evaluation of fatigue crack propagation considering nonlinear damage accumulation. Materials 2016, 9, 483. [CrossRef] [PubMed]

31. Pilegis, M.; Gardner, D.; Lark, R. An investigation into the use of manufactured sand as a $100 \%$ replacement for fine aggregates in concrete. Materials 2016, 9, 440. [CrossRef] [PubMed]

32. Safiuddin, M.; Raman, S.N.; Abdus Salam, M.; Jumaat, M.Z. Modeling of compressive strength for self-consolidating high-strength concrete incorporating palm oil fuel ash. Materials 2016, 9, 396. [CrossRef] [PubMed]

33. Bagci, M. Neural network model for moment-curvature relationship of reinforced concrete sections. Mathematical and Computational Applications 2010, 15, 66-78. [CrossRef]

34. Asteris, P.G.; Roussis, P.C.; Douvika, M.G. Feed-Forward Neural Network Prediction of the Mechanical Properties of Sandcrete Materials. Sensors 2017, 17, 1344. [CrossRef] [PubMed]

35. Asteris, P.G.; Kolovos, K.G.; Douvika, M.G.; Roinos, K. Prediction of self-compacting concrete strength using artificial neural networks. Eur. J. Environ. Civ. Eng. 2016. [CrossRef]

36. Asteris, P.G.; Tsaris, A.K.; Cavaleri, L.; Repapis, C.C.; Papalou, A.; di Trapani, F.; Karypidis, D.F. Prediction of the Fundamental Period of Infilled RC Frame Structures Using Artificial Neural Networks. Comput. Intell. Neurosci. 2016. [CrossRef] [PubMed]

37. Asteris, P.G.; Kolovos, K.G. Self-compacting concrete strength prediction using surrogate models. Neural Comput. Appl. 2017. [CrossRef]

38. Asteris, P.G.; Nozhati, S.; Nikoo, M.; Cavaleri, L.; Nikoo, M. Krill herd algorithm-based neural network in structural seismic reliability evaluation. Mech. Adv. Mater. Struct. 2018. [CrossRef]

39. Grippo, L.; Manno, A.; Sciandrone, M. Decomposition Techniques for Multilayer Perceptron Training. IEEE Trans. Neural Netw. Learn. Syst. 2016. [CrossRef] [PubMed]

40. Alexandridis, A.; Chondrodima, E.; Giannopoulos, N.; Sarimveis, H. A Fast and Efficient Method for Training Categorical Radial Basis Function Networks. IEEE Trans. Neural Netw. Learn. Syst. 2016. [CrossRef] [PubMed]

41. Efstathiadesa, C.; Baniotopoulosa, C.C.; Nazarkob, P.; Ziemianskib, L.; Stavroulakisc, G.E. Application of neural networks for the structural health monitoring in curtain-wall systems. Eng. Struct. 2007, 29, 3475-3484. [CrossRef]

42. Just-Agosto, F.; Serrano, D.; Shafiq, B.; Cecchini, A. Neural network based nondestructive evaluation of sandwich composites. Compos. Part B Eng. 2007. [CrossRef]

43. Wittmann, F.H. Fracture Mechanics of Concrete; Elsevier: Amsterdam, the Netherlands, 1983.

44. Krajcinovic, D.; Fanella, D. A micromechanical damage model for concrete. Eng. Fract. Mech. 1986, 25, 585-596. [CrossRef]

45. Bazant, Z.; Xiang, Y.; Adley, M.D.; Prat, P.C.; Akers, S. Microplane model for concrete: II: Data delocalization and verification. J. Eng. Mech. 1996, 122, 255-262. [CrossRef]

46. Caner, F.C.; Bazant, Z.P.; Cervenka, J. Vertex effect in strain-softening concrete at rotating principal axes. J. Eng. Mech. 2002, 128, 24-33. [CrossRef]

47. Lee, S.C. Prediction of concrete strength using artificial neural networks. Eng. Struct. 2003. [CrossRef]

48. Garzon-Roca, J.; Marco, C.O.; Adam, J.M. Compressive strength of masonry made of clay bricks and cement mortar: Estimation based on Neural Networks and Fuzzy Logic. Eng. Struct. 2012. [CrossRef]

49. Sahin, M.; Shenoi, R.A. Quantification and localisation of damage in beam-like structures by using artificial neural networks with experimental validation. Eng. Struct. 2003. [CrossRef] 
50. Yuen, K.Y.; Lamb, H.F. On the complexity of artificial neural networks for smart structures monitoring. Eng. Struct. 2006. [CrossRef]

51. Min, J.; Park, S.; Yun, C.B.; Lee, C.G.; Lee, C. Impedance-based structural health monitoring incorporating neural network technique for identification of damage type and severity. Eng. Struct. 2012. [CrossRef]

52. Yeung, W.T.; Smith, J.W. Damage detection in bridges using neural networks for pattern recognition of vibration signatures. Eng. Struct. 2005. [CrossRef]

53. Bakhary, N.; Hao, H.; Deeks, A.J. Damage detection using artificial neural network with consideration of uncertainties. Eng. Struct. 2007. [CrossRef]

54. Inel, M. Modeling ultimate deformation capacity of RC columns using artificial neural networks. Eng. Struct. 2006. [CrossRef]

55. Köroğlu, M.A.; Ceylan, M.; Arslan, M.H.; Ilki, A. Estimation of flexural capacity of quadrilateral FRP-confined RC columns using combined artificial neural network. Eng. Struct. 2012, 18, 357-364. [CrossRef]

56. Jørgensen, C.; Grastveit, R.; Garzón-Roca, J.; Payá-Zaforteza, I.; Adam, J.M. Bearing capacity of steel-caged RC columns under combined bendingand axial loads: Estimation based on Artificial Neural Networks. Eng. Struct. 2013. [CrossRef]

57. Cladera, A.; Marı, A.R. Shear design procedure for reinforced normal and high-strength concrete beams using artificial neural networks. Part I: Beams without stirrups. Eng. Struct. 2004. [CrossRef]

58. Cladera, A.; Mar1, A.R. Shear design procedure for reinforced normal and high-strength concrete beams using artificial neural networks. Part II: Beams with stirrups. Eng. Struct. 2004. [CrossRef]

59. Oreta, A.W.C. Simulating size effect on shear strength of RC beams without stirrups using neural networks. Eng. Struct. 2004. [CrossRef]

60. Kutuk, M.A.; Atmacab, N.; Guzelbeya, I.H. Explicit formulation of SIF using neural networks for opening mode of fracture. Eng. Struct. 2006. [CrossRef]

61. Elshafey, A.A.; Dawood, N.; Marzouk, H.; Haddara, M. Crack width in concrete using artificial neural networks. Eng. Struct. 2013. [CrossRef]

62. Pendharkar, U.; Chaudharyb, S.; Nagpala, A.K. Neural network for bending moment in continuous composite beams considering cracking and time effects in concrete. Eng. Struct. 2006. [CrossRef]

63. Mohammed, A.; Sakr, M.A.; Sakla, S.S.S. Long-term deflection of cracked composite beams with nonlinear partial shear interaction: A study using neural networks. Eng. Struct. 2009. [CrossRef]

64. Sigurdardottir, D.H.; Glisic, B. The neutral axis location for structural health monitoring: An overview. Journal of Civil and Structural Health Monitoring. J. Civ. Struct. Health Monit. 2015, 5, 703-713. [CrossRef]

65. Martin, O.; Lopez, M.; Martin, F. Artificial neural network for quality control by ultrasonic testing in resistance spot welding. J. Mater. Process. Technol. 2007, 183, 226-233. [CrossRef]

66. Atici, U. Prediction of the strength of mineral admixture concrete using multivariable regression analysis and an artificial neural network. Expert Syst. Appl. 2011, 38, 9609-9618. [CrossRef]

67. Oreta, A.W.C.; Kawashima, K. Neural network modeling of confined compressive strength and strain of circular concrete columns. J. Struct. Eng. 2003, 129, 554-561. [CrossRef]

(C) 2018 by the authors. Licensee MDPI, Basel, Switzerland. This article is an open access article distributed under the terms and conditions of the Creative Commons Attribution (CC BY) license (http:/ / creativecommons.org/licenses/by/4.0/). 